\title{
Floristic composition and across-track reflectance gradient in Landsat images over Amazonian forests
}

\author{
Javier Muro ${ }^{\mathrm{a}}$, Jasper Van doninck ${ }^{\mathrm{a}}$, Hanna Tuomisto ${ }^{\mathrm{a}}$, Mark A. Higgins ${ }^{\mathrm{b}}$, \\ Gabriel M. Moulatlet ${ }^{\mathrm{a}}$, Kalle Ruokolainen ${ }^{\mathrm{a}, *}$ \\ ${ }^{a}$ Amazon Research Team, Department of Biology, University of Turku, FI-20014 Turku, \\ Finland \\ ${ }^{b}$ Department of Global Ecology, Carnegie Institution for Science, Stanford, CA 94305, USA
}

\begin{abstract}
Remotely sensed image interpretation or classification of tropical forests can be severely hampered by the effects of the bidirectional reflection distribution function (BRDF). Even for narrow swath sensors like Landsat TM/ETM+, the influence of reflectance anisotropy can be sufficiently strong to introduce a crosstrack reflectance gradient. If the BRDF could be assumed to be linear for the limited swath of Landsat, it would be possible to remove this gradient during image preprocessing using a simple empirical method. However, the existence of natural gradients in reflectance caused by spatial variation in floristic composition of the forest can restrict the applicability of such simple corrections. Here we use floristic information over Peruvian and Brazilian Amazonia acquired through field surveys, complemented with information from geological maps, to investigate the interaction of real floristic gradients and the effect of reflectance anisotropy on the observed reflectances in Landsat data. In addition, we test the assumption of linearity of the BRDF for a limited swath width, and whether different primary non-inundated forest types are characterized by different magnitudes of the directional reflectance gradient. Our results show that a linear function is adequate to empirically correct for view angle effects, and that the magnitude of the across-track reflectance gradient is independent of floristic
\end{abstract}

\footnotetext{
* Corresponding author

Email address: kalle.ruokolainen@utu.fi (Kalle Ruokolainen)
}

Preprint submitted to ISPRS Journal of Photogrammetry and Remote Sensing June 7, 2016 
composition in the non-inundated forests we studied. This makes a routine correction of view angle effects possible. However, floristic variation complicates the issue, because different forest types have different mean reflectances. This must be taken into account when deriving the correction function in order to avoid eliminating natural gradients.

Keywords: Amazonia, BRDF, Landsat, ferns and lycophytes, floristic composition, Melastomataceae, radiometric correction, tropical forests

\section{Introduction}

Amazonian rain forests, especially the non-inundated ones, were traditionally considered rather homogeneous in terms of species composition (Encarnación, 1985 Pires and Prance, 1985, Salo et al. 1986). More recently, however, several

5 authors have shown that plant species composition in these forests is significantly related to physical and chemical characteristics of soils at different spatial scales, from local to regional (Tuomisto et al., 1995, Ruokolainen et al., 1997, 2007; Tuomisto et al., 2003a b c, Phillips et al., 2003, Costa et al., 2005: Duque et al. 2005, Kinupp and Magnusson, 2005: Bohlman et al., 2008; Kristiansen 10 et al. 2012, Figueiredo et al. 2014). These findings have increased the need for a more detailed identification and mapping of spatial variation in plant species composition to support rainforest conservation and land use planning efforts. Interpretation of satellite imagery with high spatial resolution $(10-100 \mathrm{~m})$, such as Landsat, is crucial for such mapping to be possible over large areas.

Remote sensing of tropical rain forests is associated with several challenges, one of the most obvious being the persistent cloud cover in these high-rainfall regions. Another challenge is that reflectance differences among forest types are often subtle (Sesnie et al. 2010; Higgins et al., 2015). This makes it necessary to utilize the 8-bit satellite imagery (such as Landsat TM/ETM+) up to its radiometric limits, which in turn makes the interpretations more prone to errors due to radiometric distortions (Toivonen et al., 2006, Higgins et al., 2011). The importance of a careful radiometric and atmospheric correction is therefore 
evident.

n In recent years, especially since the opening of the Landsat archive (Wulder

25 et al. 2012), considerable effort has been put to the operational development and distribution of atmospherically corrected surface reflectance products (Roy et al. 2010 Ju et al., 2012). Because of the narrow field of view of Landsat $\left(7.5^{\circ}\right.$ each side of nadir), the bidirectional reflectance distribution function (BRDF) effects are often ignored in the atmospheric correction, and a Lamber-

30 tian behaviour of the surface is assumed (Masek et al. 2006, Ju et al., 2012, Roy et al., 2014). However, studies over Amazonian forests have demonstrated that directional scattering, which gives rise to an across-track gradient in digital number, can be strong (Nagol et al. 2015), and hence nullify the spectral separability of different forest types (Toivonen et al., 2006) or suggest the existence 35 of vegetation patterns where none exist (Ruokolainen and Tuomisto, 1998).

Several authors have suggested methods for BRDF correction of Landsat imagery. Roy et al. (2008) developed a multi-temporal data fusion for Landsat and MODIS using the MODIS BRDF/Albedo land surface characterization product (Schaaf et al., 2002) to correct directional effects in Landsat, and variations on

40 this approach have since been evaluated over different sites (Li et al., 2010,2012 Flood, 2013 Shuai et al. 2014). Given the vast areas covered by closed canopy, this method can be expected to be applicable over Amazonian forests in spite of the spatial resolution gap between both sensors. A more severe restriction is the persistent cloud cover in tropical areas. Generation of MODIS BRDF parame45 ters assumes the availability of several cloud-free observations during a 16-day period (Schaaf et al. 2002). Even in the case of a cloudfree Landsat acquisition, the required number of MODIS observations during the adjacent days may not be reached. Furthermore, no MODIS BRDF parameters are available for the period before the start of MODIS operation in 2000. A different approach was so suggested by Flood et al. (2013) for Landsat TM/ETM+ imagery over Eastern Australia. This method exploits the availability of multi-temporal acquisitions over this region to calculate BRDF parameters at the Landsat spatial resolution. Consequently, it is not applicable in areas with only occasional cloud-free 
conditions.

As an alternative to multi-sensor or multi-temporal approaches, empirical scene-based normalizations have been suggested by some authors (Toivonen et al. 2006: Hansen et al., 2008, Broich et al., 2011). These derive the relationship between the position of a pixel in the image and its digital number or reflectance through linear regression, and consecutively use this relationship to normalize the across-track gradient. This method relies on a number of assumptions. Firstly, it is assumed that the BRDF, and the brightness variation it gives rise to, is linear over a uniform land surface in Landsat's narrow field of view. Secondly, it is assumed that there are no east-west gradients in the imagery other than those caused by directional reflectance effects (Roy et al.) 65 2016). Hansen et al. (2008) aimed to ensure this by deriving the regression coefficients only for forested pixels (as inferred from a MODIS forest mask), rather than for all pixels in the scene. However, not all forests are identical, and gradual or abrupt changes in floristic composition may exist and affect reflectance properties even within forested areas, and this could invalidate the empirical correction.

In this study, we investigate the reliability of empirical across-track reflectance gradient corrections for two regions in Peruvian and Brazilian Amazonia. First, we use in situ data on floristic composition to test if adequate corrections of Landsat TM/ETM+ imagery is obtained using simple linear models, 75 and if variation in species composition of the forest confounds the correction. Then we test an earlier suggestion (Toivonen et al., 2006) that the radiometric gradient has different magnitudes over different kinds of forest in Amazonia. If different corrections are needed for different kinds of forest, the demand for ground truth data would increase and routine radiometric correction be severely hampered. We use a large image dataset combined with geological data (which acts as proxy for forest species composition) to quantify how much error is introduced if compositional variation in the forest is ignored. This will help in assessing whether or not these relatively simple, empirical angular normalization techniques are appropriate for a given application. 


\section{Study area and data sets}

\subsection{Study area}

This study was conducted in tropical rain forests of the Amazonian lowlands in northern Peru and western Brazil (Fig. 1). The area is covered largely by undisturbed primary terra firme (non-inundated) forest under closed canopy. Areas that are sporadically, seasonally or permanently inundated occur along rivers. Climate is tropical, humid, and almost aseasonal. In the city of Iquitos, which is situated near the Peruvian study area, the mean monthly temperature is $25-27^{\circ} \mathrm{C}$ throughout the year and annual precipitation is approximately $3100 \mathrm{~mm}$ (Marengo, 1998). The city of Eirunepé, near the Brazilian site on the Juruá River, experiences a mean monthly temperature of approximately $25^{\circ} \mathrm{C}$ and an annual precipitation of $2195 \mathrm{~mm}$ (http://inmet.gov.br/portal/). Elevation ranges from 100 to $250 \mathrm{~m}$ above sea level in most of the study area, with a few precipitously hilly areas exceeding $400 \mathrm{~m}$.

Two geological formations are exposed at the surface over most of the study area. These are known in Peru as the Pebas Formation and the Nauta Formation, and in Brazil as the Solimões Formation and the Içá Formation, respectively. For clarity, only the Peruvian names will be used here. The Pebas Formation consists of poorly weathered, relatively cation-rich (by Amazonian standards) clay sediments that were deposited under low-energy semi-marine or lacustrine conditions of the Pebas Embayment. The Nauta formation consists of more weathered, cation-poor sediments with coarser texture that were deposited on top of the Pebas Formation under higher-energy deltaic to fluvial conditions (Räsänen et al., 1995, Rebata-H. et al., 2006, Hoorn et al., 2010). The cation concentration in the soils derived from the Pebas Formation is about one order of magnitude higher than that in the Nauta Formation. This difference in soils is reflected in the species composition of the primary terra firme forest, and gives rise to a plant species turnover of 80-90\% across the geological boundary (Higgins et al. 2011). A third distinct unit of the terra firme landscape is formed by river terraces of sedimentary deposits from Andean origin dated from 

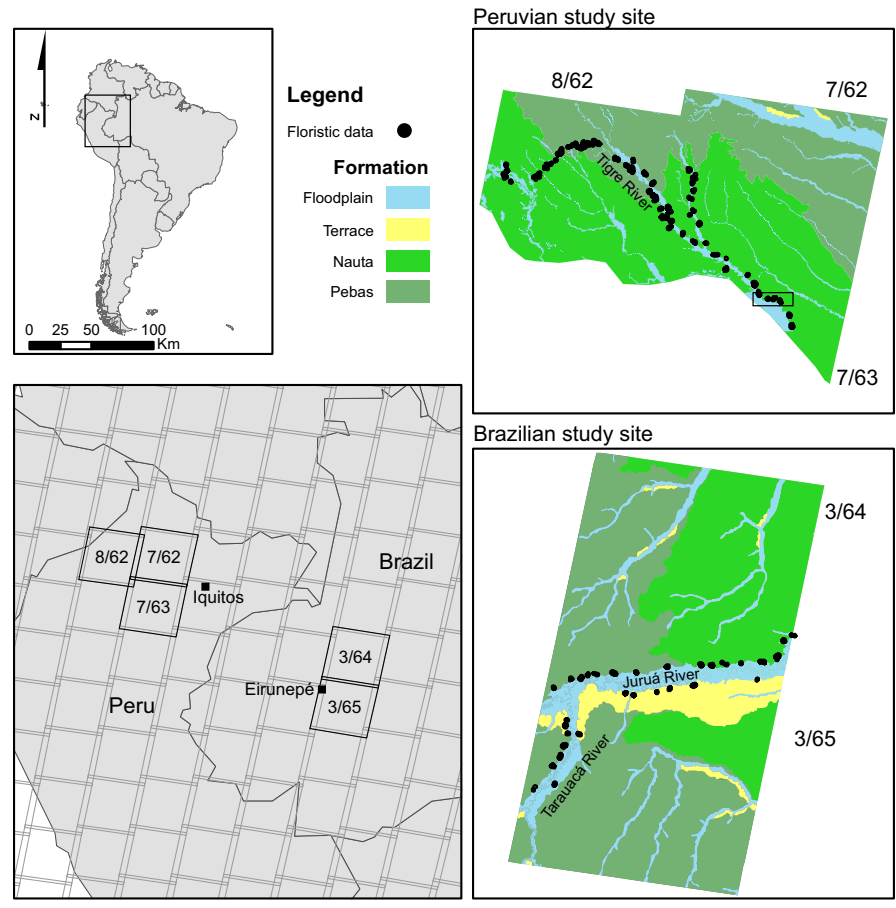

Brazilian study site

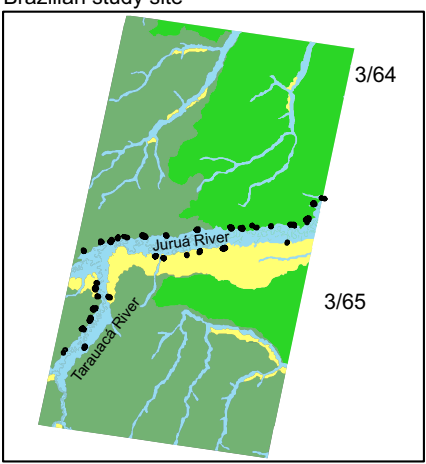

Figure 1: Locations of the Landsat images used, with indication of path/row combination, the main geological formations in the study area, and the sampling sites where floristic information was collected. The location of the image detail in Fig. 3 in the Peruvian study site is indicated by the box.

mid/late Pleistocene. In terms of sedimentation environment and soil nutrient content, the terraces are similar to the Nauta formation. The main differences between the two is that terraces are practically flat in topography (Irion and Kalliola, 2009).

The digitized geological maps used in this study were obtained from the Instituto Geológico Minero y Metalúrgico (INGEMMET, http://www.ingemmet.gob.pe) and the Geological Survey of Brazil (CPRM, http://geobank.sa.cprm.gov.br). The boundaries between the Pebas and Nauta Formations in these maps were modified according to the discontinuity identified in Landsat imagery and Shuttle Radar Topography Mission (SRTM) elevation data (Higgins et al., 2011). The histograms in Fig. 2 show that, for both study sites, the Pebas Forma- 
tion is characterized by slightly lower elevations with less steep slopes than the Nauta Formation. There is no difference in terrain orientation between the two formations in either site.
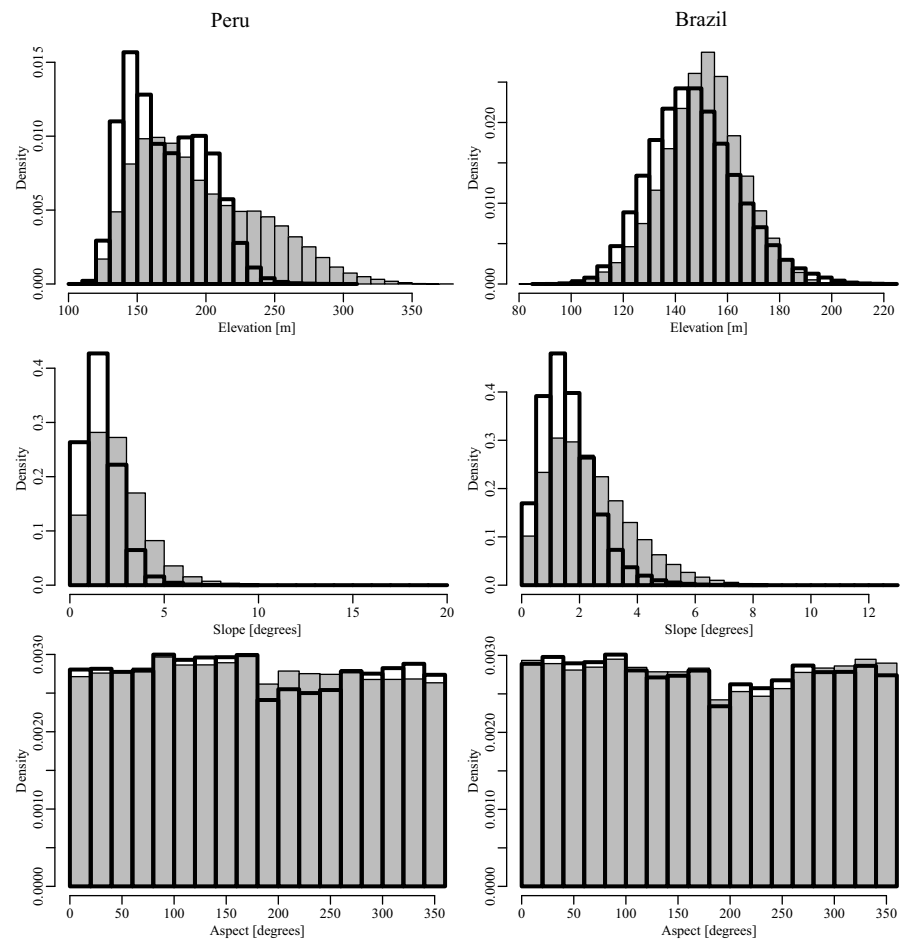

Figure 2: Frequency distribution plots of elevation (top), slope (middle) and aspect (bottom) for the Peruvian and Brazilian study sites, for the Pebas (thick lines) and Nauta (shaded) Formations.

\subsection{Floristic data}

The surface reflectance of dense forests, as observed by satellite sensors operating in the optical domain, is mostly determined by properties of the forest canopy, including tree species composition. Because collection of field data on canopy species composition in these high-diversity forests is difficult and time consuming, approaches have been developed to use floristic variation in more easily observable understory plant groups as indicators of floristic variation in 
canopy trees (Ruokolainen et al., 1997, 2007). Here we use a floristic dataset of two such indicator groups, pteridophytes (ferns and lycophytes) and the Melastomataceae. Both groups have been found to reproduce well the floristic patterns observed in trees (Tuomisto et al., 1995; Ruokolainen et al., 1997, 2007). The data have been inventoried using a standard procedure (Tuomisto et al. 2003a), where presence-absence of different species was recorded along $500 \mathrm{~m}$ long and $5 \mathrm{~m}$ wide transects. Two sets of such transects are used here: 105 transects in Peru, inventoried in 2005-2006 and 45 transects in Brazil, inventoried in 2012. Both sets were purposefully placed to sample the Pebas/Nauta boundary, and eleven of the Brazilian transects sample terraces of the Juruá and Tarauacá rivers (Fig. 1). The Peruvian dataset is described in more detail in (Higgins et al. 2011) and (Higgins et al., 2012).

\subsection{Landsat data}

Two sets of Landsat TM/ETM+ images are used here. The first consists of two image mosaics, one covering the Peruvian and the other covering the Brazilian field inventory sites (Fig. 1). The five selected and visually inspected cloudfree Level $1 \mathrm{~T}$ images used to produce these mosaics (Table 1) were obtained through the USGS EarthExplorer website (http://earthexplorer.usgs.gov/). For the Brazilian study area, the two images were acquired during the same overpass, so they could be easily combined into a seamless mosaic. For the Peruvian site, two images were obtained during the same overpass, but the third was acquired seven years later, but with a difference in calendar days of only 17 days, and was normalized with respect to the other two images using histogram matching in the area of overlap. The seasonal 17 day gap between the acquisitions is sufficiently small to ensure that vegetation throughout the mosaic is at the same phenological state. Due to the persistent cloud cover, there were no images available from these adjacent paths with a gap smaller than seven years, with such a small seasonal difference. Also, there is a time gap between the acquisition of the images and the field data collection for both sites. How- 
changes in floristic composition occurred during this period.

Table 1: Landsat L1T images used to construct the mosaics

\begin{tabular}{lllllll}
\hline Area & Path & Row & Date & Sensor & Solar azimuth & Solar elevation \\
\hline Peru & 7 & 62 & $21 / 08 / 1999$ & ETM+ & $62.60^{\circ}$ & $56.70^{\circ}$ \\
Peru & 7 & 63 & $21 / 08 / 1999$ & ETM+ & $60.85^{\circ}$ & $55.83^{\circ}$ \\
Peru & 8 & 62 & $08 / 09 / 2006$ & TM & $73.32^{\circ}$ & $60.46^{\circ}$ \\
Brazil & 3 & 64 & $04 / 08 / 2006$ & TM & $52.56^{\circ}$ & $51.76^{\circ}$ \\
Brazil & 3 & 65 & $04 / 08 / 2006$ & TM & $51.33^{\circ}$ & $50.70^{\circ}$ \\
\hline
\end{tabular}

The second image dataset comprises 45 predominantly cloud-free Landsat TM/ETM+ images acquired between 1987 and 2011 throughout the year. Seventeen, 14 and 14 acquisitions were used for the scenes with path/row combination 003/064, 007/062 and 008/062, respectively. These three scenes cover a boundary of the Pebas and Nauta formations in Brazil and northern Peru. Contrary to the two mosaics described above, for which the original Landsat images were used, we here downloaded the Landsat Surface Reflectance Climate Data Record (CDR) images through EarthExplorer portal.

These are generated using the Landsat Ecosystem Disturbance Adaptive Processing System (LEDAPS, version 2.1.0) algorithm which includes conversion of radiance to reflectance values and application of the MODIS atmospheric correction (Masek et al., 2006). As a result, reflectance differences resulting from varying atmospheric conditions between images acquired during different seasons are minimised. The CDR images are accompanied by a number of automatically generated mask bands. Pixels that were flagged in any of the bands as cloud, cloud shadow, cloud buffer, or water were excluded from further analyses. Seasonally inundated forests (i.e., river floodplains) were also masked based on the available geological maps. 


\subsection{Quantification of floristic gradient}

The field inventory resulted, for each $5 \mathrm{~m}$ by $500 \mathrm{~m}$ transect, in a listing of the presence or absence of species of ferns, lycophytes and Melastomataceae. Typically plant species occurrences are correlated with each other so that one can reduce the dimensionality of the data table by finding eigenvectors that summarize the intercorrelated descriptors (species). A simple principal components analysis is, however, not an ecologically suitable method because both ecological theory and empirical data show that species abundances have unimodal responses to environmental variables (Legendre and Legendre, 2012). Therefore we first calculated an ecologically meaningful species compositional distance (one-complement of Jaccard index of similarity (Jaccard, 1912)) between each pair of transects separately for the Peruvian and Brazilian transects. Then ¿we used non-metric multidimensional scaling analysis (NMDS) (Legendre and Legendre, 2012) to find the best unidimensional representation of the multidimensional variation in each of the two data matrices. NMDS is an iterative method that aims to map objects (transects) into a specified number of dimensions such that the rank order of the distances as measured from the ordination solution are as similar as possible to those in the original dissimilarity matrix. The NMDS scores obtained for the Peruvian dataset have previously been observed to closely correlate with soil cation concentration (Higgins et al., 2011 2012).

\subsection{Testing the linearity and forest-type independence of BRDF}

In order to test both the linearity of the BRDF for the limited swath width of Landsat and the forest-type independence of the empirically observed reflectance gradient, we fitted a cubic trend surface (Legendre and Legendre, 2012) to the floristic data and remotely sensed data of the sampling sites:

$$
D N=a+b \Gamma+c \nu+d \Gamma \nu+e \Gamma^{2}+f \nu^{2}+g \Gamma \nu^{2}+h \Gamma^{2} \nu+i \Gamma^{3}+j \nu^{3},
$$


where $D N$ is the Landsat digital number corresponding to the sampling site, $\Gamma$ is the column number corresponding to the site, and $\nu$ is the NMDS-score of the site (all unitless). Column number $\Gamma$ here refers to the column number as it would be in the raw, unprocessed image. Since we here used rectified Level $1 \mathrm{~T}$ data, we used reconstructed column numbers. These were obtained by calculating the perpendicular distance from the centroid of a segment or pixel to the western edge of the Landsat image or mosaic, and dividing this distance by the spatial resolution of the image $(30 \mathrm{~m})$. The position of the western edge was determined manually by fitting a line through the westernmost non-void pixels of the mosaic.

In order to obtain a representative $D N$ for each $5 \mathrm{~m}$ by $500 \mathrm{~m}$ field sampling transect, we first performed a segmentation on each Landsat mosaic (Fig. 3) to group the individual Landsat pixels into relatively homogeneous objects or segments. The segmentation used all six reflective Landsat bands, and was performed in eCognition v8.8 (parameter settings: scale $=20$, shape $=0.4$, compactness $=0.4)$. Digital numbers of all pixels within each segment were then averaged, for each band separately, and this average was assigned to the segment. Representative $D N$ values for the transects were then calculated from the segment or segments it traversed. When a transect fell entirely within one segment, the spectral values for that segment were assigned to the transect. In case a transect crossed two or more segments, a weighted average over these segments was calculated, with as weights the proportional length of the transect overlying the segment. Through this procedure we acknowledge that local edaphic variation can control plant species composition at spatial resolutions smaller than our 500-m-long sampling transects (Tuomisto et al., 1995, Poulsen et al. 2006), and that edaphically induced floristic variation is detectable in $D N$ values (Tuomisto et al., 1995, 2003a; Higgins et al., 2011; Thessler et al., 2005). Segmentation also removes undesired noise that can result from small-scale topographic features, while keeping the directional component unaffected.

In the first step, only the two first terms of Eq. 1 were used to build the model. This model captures the proportion in $D N$ variance that is linearly 


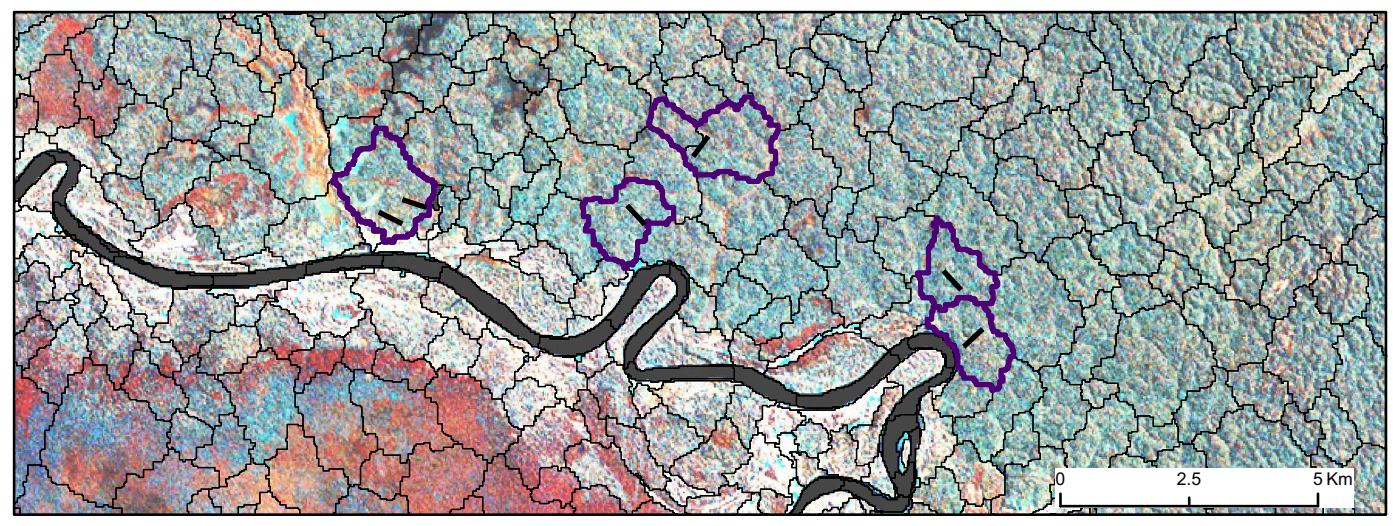

Figure 3: Example of image segmentation for the Peruvian study site (red=band 4, blue=band 5 , green=band 7). Straight black lines indicate the field sampling transects, and polygons highlighted in blue indicate the segments that were used to derive digital numbers for each transect. See Fig. 1 for location of image detail.

explained by $\Gamma$. In the next step, the term in $\nu$ was added to the model to capture the proportion of $D N$ variance that is explained by column number and NMDS-score together but without any interaction between the two. Finally, the remaining terms were added step-wise into the model, starting from the ones with the largest adjusted coefficient of determination $\left(\bar{R}^{2}\right)$ and proceeding to those with smaller $\bar{R}^{2}$ until the next one to be added was not statistically significant $(p=0.05)$. The assumption of linearity can be accepted if the addition of higher order polynomial terms containing the column number $\Gamma$ does not increase the adjusted coefficient of determination. On the other hand, if adding first or higher order terms containing NMDS score $\nu$ increases $\bar{R}^{2}$, then floristic variation within the rain forest can be concluded to influence the empirical estimation of the across-track reflectance gradient. This analysis was performed separately for the Peruvian and Brazilian study areas and for each spectral band. 


\subsection{Comparison of reflectance gradient for different geological formations}

The magnitude of the reflectance gradient is influenced by the optical properties of the surface. Different species of the forest canopy may have different

260

275

reflectance gradient was derived as follows:

$$
\rho=a+b \Gamma,
$$

where $\rho$ is the surface reflectance of the pixel. In each of the 45 Landsat images, 20,000 randomly selected pixels were placed over forested areas, half on the Pebas Formation and half on the Nauta Formation, and $b$ was derived for both formations separately. Values of $b$ obtained in this way are referred to as "stratified" reflectance gradients in further sections. Additionally, an "unstratified" reflectance gradient was calculated for each image without discriminating between Pebas and Nauta, but with masking of other formations such as terraces 

trend in Amazonian rain forest area of decreasing soil fertility from west to east (Räsänen et al., 1995; Hoorn et al., 2010). 

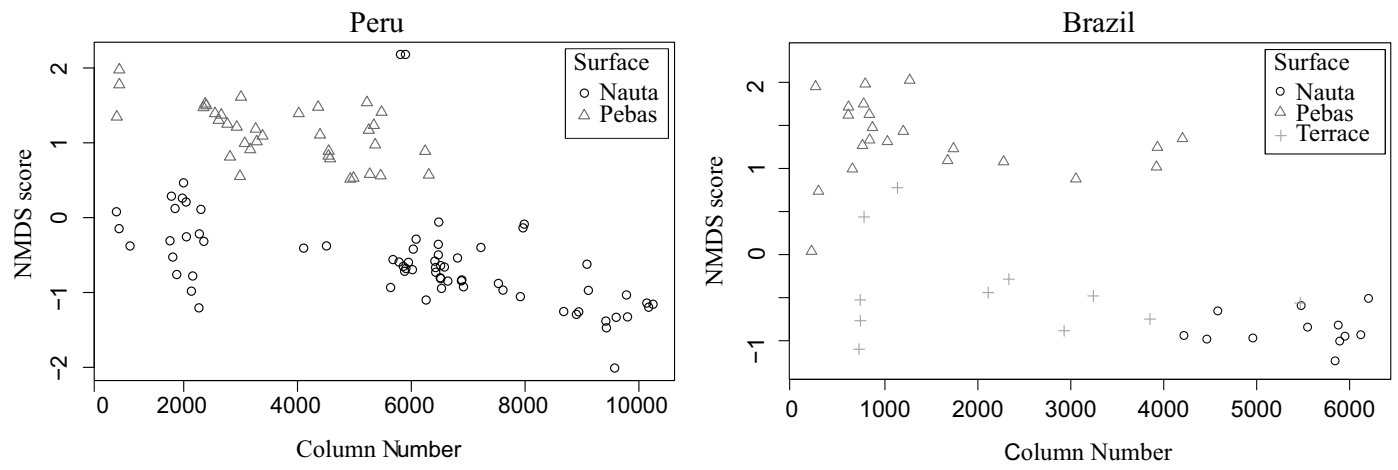

Figure 4: NMDS score versus image column number for the Peruvian and Brazilian study sites, with indication of geological formation.

How digital numbers corresponding to each transect relate to column number and NMDS score is shown in Fig. 5 for the Peruvian transects and in Fig. 6 for the Brazilian ones. The value of the third variable (NMDS score for the $\Gamma$ - $D N$ plot, column number for the $\nu$ - $D N$ plot) is indicated by colours. These figures show that erroneous conclusions may be drawn when only one explanatory variable is taken into account. E.g., a strong possible correlation between 320 NMDS score and digital number could be suggested when anisotropy is ignored. In reality, however, the increase in NMDS score with increasing column number is only limited - if present at all - for a given small range of column numbers. The decrease of digital number with increasing column number, on the other hand, is the result of an interplay of effects of anisotropy and floristic composition.

\subsection{Reflectance gradient modelling}

Adjusted coefficients of determination of the iterative application of Eq. 1 are given in Table 2 Regressions with pixel value as the dependent variable and the first order term of column number as the only explanatory variable gave consistently high $\bar{R}^{2}$ values. Adding the first order term of the NMDS score did not improve the $\bar{R}^{2}$ for visible light bands in either study area, but for the infrared bands it did. Then $\bar{R}^{2}$ increased most for band 4 in Peru (0.102) and 
for band 7 in Brazil (0.051). For the other bands, increase in $\bar{R}^{2}$ was detectable but rather small (0.017-0.022). Adding higher order terms of the NMDS score increased $\bar{R}^{2}$ little or not at all, except for band 4 in Brazil, where the increase was 0.154 .

\subsection{Pebas/Nauta difference of the reflectance gradient}

An empirical reflectance gradient for the forests on the two geological formations (Pebas and Nauta) was obtained by regressing surface reflectance against column number (Eq. 2) using 10,000 random points for each geological formation. This was done separately for each of the 45 Landsat images and each spectral band. Mean slopes and standard deviations of these gradients are given in Table 3, together with the differences between the mean slopes on the Pebas and Nauta formations. A paired t-test was performed to check if significant differences between the slopes on the two formations exist. Because the Shapiro-Wilks test for normality indicated that 10 out of 24 Pebas Formation datasets and 4 out of 24 Nauta Formation datasets were not normally distributed (at $\mathrm{p}=0.05$ ), the non-parametric Wilcoxon signed-rank test was also used. Results of the t-test and the Wilcoxon test were almost identical, however. Both revealed significant differences $($ at $p=0.05$ ) between the mean slopes in the infrared bands for scenes 003/064 and 008/062. In scene 003/064, the reflectance gradient is stronger (more negative) for the Pebas than for the Nauta Formation which gives a negative difference, but in scene 008/062 the situation was reversed and the difference was positive. As a result, differences for all data pooled are much smaller, and not significant for either test at $\mathrm{p}=0.05$.

In Table 4 , the slopes obtained for the Pebas and Nauta formation are combined to calculate a stratified reflectance gradient. This is simply done by, for each image, taking the average of the slopes as measured over the Pebas and Nauta formations separately. The stratified slopes are then compared to the unstratified slopes, which were obtained by linear regression of digital number versus column number for pixels over both formations combined. A significant 
difference between the stratified and unstratified slopes can be observed for the green bands and all infrared bands, for each of the image scenes. The sign of this difference is opposite for the Brazilian scene 003/064 with respect to the two Peruvian scenes. Differences between stratified and unstratified slopes are linked to the relative spatial pattern of the two geological formations and the associated forest cover. In the Brazilian scene, the Nauta Formation (with forests of lower reflectance in the infrared) dominates the eastern side of the image and the Pebas Formation (with forests of higher reflectance) the western side. In the Peruvian scenes, the situation is the opposite. In addition, the geological interface is oriented in a generally northwest-southeast direction in the Peruvian site but north-south (almost perpendicular to the Landsat scan direction) in the Brazilian site. This results in a much larger difference between the stratified 375 and unstratified slopes in the Brazilian scenes.

\section{Discussion}

Our analyses showed that the single most important predictor of the digital numbers corresponding to in situ sampling sites in terra firme forests was the east-west position of the site in a Landsat mosaic. The largest part of the variability in $D N$ was explainable as a linear function of column number $(\Gamma)$. This was the case for all spectral bands and in both study areas (Brazil and Peru). The increase in $\bar{R}^{2}$ when higher-order polynomial terms of column number were added to the model was small or statistically insignificant. This result suggests that a linear relationship between column number — which represents sensor view angle - and image digital number — which represents surface reflectancecan be used to correct for bidirectional reflection distribution function (BRDF) in Landsat images over Amazonian terra firme forests. The same principle may be applicable to other high resolution imagery with a similar swath width.

It should be noted that the topography in our study area is relatively flat. At the local scale, the slopes of the hills can be steep, but as the hills themselves rarely exceed $50 \mathrm{~m}$ in height, their effect on surface reflectance is smaller than 
in areas of truly accented topography. There is a discontinuity in this respect between the Pebas and Nauta Formation, as the former typically has flatter topography than the latter. With increasing topographic relief, the range of possible sun-terrain-sensor configurations will increase. At some point it will then become necessary to apply more complex topographic/BRDF corrections, and these may be non-linear (Li et al., 2012, Flood et al., 2013).

We found that digital numbers of the blue, green and red Landsat bands were unrelated to floristic composition, as represented by the NMDS scores $(\nu)$. This is in accordance with the findings of Higgins et al. (2012) who stated that "no information about floristic patterns is lost by excluding bands 1-3 from image display and manual image interpretation". Data in the visible bands can, however, assist in discriminating primary forest from other land cover types (Sesnie et al., 2010).

In the near and shortwave infrared bands, addition of NMDS scores (which represent position along the main floristic gradient observed in the forests) in the iterative regression analysis increased $\bar{R}^{2}$ in both study areas. In other words, differences in floristic composition can be observed using the relatively limited spectral and radiometric resolution of the Landsat TM/ETM+ sensors. This has implications for simple, scene-based empirical BRDF correction methods such as those suggested by (Hansen et al. 2008). It was shown in Fig. 4 that a floristic east-west gradient exists in both study sites. This creates a natural, real trend of reflectance values in the near and shortwave infrared wavelengths that coincides with the reflectance gradient resulting from reflectance anisotropy. Such covariation can result in an over- or underestimation of the magnitude of either one gradient if it is studied without considering the other.

When the empirical reflectance gradient was derived over forests covering the Pebas and Nauta formation separately, pooling all the images, no significant difference between their slopes could be found for any of the visible or 420 infrared bands. Significant differences in the infrared bands were detected for two of the three scenes, albeit with different signs. These may result from scene-specific properties such as subtle topographic or floristic patterns within 
a single geological formation, residual atmospheric contamination in some images, or unmasked clouds and cloud shadows. In conclusion, even though plant species compositions on the two formations are very different, this seems to have little or no effect on the directional scattering properties of the vegetation canopy for the limited swath width of the Landsat sensor.

Even though reflectance gradients obtained for the Pebas and Nauta formation are quite similar, it is important to notice that there is a difference in the absolute reflectance of the forest types covering these formations. If such floristic patterns are not taken into account when calculating an empirical reflectance gradient for a Landsat scene, the obtained model may differ significantly from what is needed for a correct normalization of viewing angle effects. In this study, the maximum difference between the unstratified and the stratified reflectance ${ }_{435}$ gradient was approximately $3 \times 10^{-6}$, or more than $50 \%$ of the stratified gradient. A single Landsat image has a width of approximately 8000 columns. When using the unstratified instead of the more reliable stratified reflectance gradient for normalization to zenith view angle (maximum 4000 columns), an error in corrected surface reflectance of up to $1.2 \%$ is introduced in the NIR band. This can be enough to hamper image interpretation or classification when studying subtle floristic patterns.

The magnitude of the difference between stratified and unstratified slopes can be expected to be related to the orientation of the boundary between forest types. To remove the reflectance gradient from Landsat images over regions characterized by a north-south-oriented interface between geological/floristic formations, an empirical gradient should be determined after stratification of the satellite image according to geology. Since no consistent significant difference in the slope was found for the two different formations, the average value over these strata could be used to normalize the entire scene. In the case of east-westoriented boundaries between formations, such stratification is less crucial, since the difference between the stratified and unstratified reflectance gradients will be small. However, failure to separate between the formations could lead to larger scatter around the regression line, and hence less accurate quantification of the 
slope. Effects of gradual vegetation changes within a single geological formation are not accounted for using this approach. Such effects can be expected to be smaller than across-formations effects (Fig. 4), but their proper verification would require more extensive field data.

\section{Conclusions}

This paper aimed at investigating the validity of empirical, linear, scenebased view angle normalization approaches for Landsat data over Amazonian rainforest. Such a radiometric correction is indispensable for the correct classification of different primary terra firme forest types, which are radiometrically very similar. We investigated the interrelation between floristic gradients and reflectance gradients introduced by the bidirectional reflection distribution function with the help of an extensive dataset of in situ field observations of indicator species. Results showed that the reflectance of a pixel is largely defined by its position in the Landsat image in the east-west direction, and that this relationship can be considered to be linear for the limited swath width of Landsat TM/ETM+. For the infrared bands, but not for the visible light bands, surface reflectance was also related to floristic composition. Therefore, empirical view angle corrections need to take the floristic variation in the forests into account to avoid producing erroneous results. A second part of this study investigated whether different forest types, identified by the geologic formation on which they grow, are characterized by a similar magnitude of the BRDF-induced reflectance gradient. No consistent differences could be found for the reflectance gradient in any spectral band.

Extensive floristic datasets, as the one used in this study, are generally not available for image preprocessing over extensive areas. Whether simple regression-based angular corrections that ignore floristic variability are appropriate depends on the application. If the aim of a study is to map deforestation, the radiometric errors introduced by ignoring floristic variation are probably trivial. If the aim is to map the floristic variation itself, the errors can be 
detrimental. A possible improvement for empirical view angle normalization methods could be to first stratify the images based on geological data, which can serve as a rough proxy for vegetation composition, and deriving view angle correction coefficients based on these strata.

\section{Acknowledgments}

The study was technically supported by the University of Turku Laboratory of Geoinformatics (UTU-LCC). We thank the Peruvian and Brazilian authorities and the local villages for permission to carry out field work, and Universidad Nacional de la Amazonía Peruana (UNAP, Iquitos - Peru), Instituto de Investigaciones de la Amazonía Peruana (IIAP, Iquitos - Peru) and Instituto Nacional de Pesquisas da Amazônia (INPA, Manaus - Brazil) for logistic support. We are grateful to numerous persons who collaborated in the field, especially Glenda Cárdenas and Nelly Llerena. The study was funded by Academy of Finland grants to HT. Financial support for MH was provided by the National Science Foundation, the American-Scandinavian Foundation, and Duke University. At the time of field work in Brazil, GM was based at INPA.

\section{References}

Bohlman, S.A., Laurance, W.F., Laurance, S.G., Nascimento, H.E., Fearnside, P.M., Andrade, A., 2008. Importance of soils, topography and geographic distance in structuring central Amazonian tree communities. Journal of Vegetation Science 19, 863-874.

Broich, M., Hansen, M.C., Potapov, P., Adusei, B., Lindquist, E., Stehman, S.V., 2011. Time-series analysis of multi-resolution optical imagery for quantifying forest cover loss in sumatra and kalimantan, indonesia. International Journal of Applied Earth Observation and Geoinformation 13,

1] 277-291. URL: http://www.sciencedirect.com/science/article/pii// S0303243410001340, doi $10.1016 / \mathrm{j} \cdot \mathrm{jag} \cdot 2010.11 .004$ 
Costa, F.R.C., Magnusson, W.E., Luizao, R.C., 2005. Mesoscale distribution patterns of amazonian understorey herbs in relation to topography, soil and watersheds. Journal of Ecology 93, 863-878.

Duque, A.J., Duivenvoorden, J.F., Cavelier, J., Sánchez, M., Polanía, C., León, A., 2005. Ferns and Melastomataceae as indicators of vascular plant composition in rain forests of Colombian Amazonia. Plant Ecology 178, 1-13.

Encarnación, F., 1985. Introducción a la Flora y Vegetación de la Amazonía peruana: estado actual de los estudios, medio natural y ensayo de claves de la determinación de las formaciones vegetales en la llanura amazónica. Candollea $40,237-252$.

${ }_{520}$ Figueiredo, F.O.G., Costa, F.R.C., Nelson, B.W., Pimentel, T.P., 2014. Validating forest types based on geological and land-form features in central Amazonia. Journal of Vegetation Science 25, 198-212.

Flood, N., 2013. Testing the local applicability of MODIS BRDF parameters for correcting Landsat TM imagery. Remote Sensing Letters 4, 793-802. 525 doi $10.1080 / 2150704$ X.2013.798709.

Flood, N., Danaher, T., Gill, T., Gillingham, S., 2013. An operational scheme for deriving standardised surface reflectance from Landsat TM/ETM+ and

口 SPOT HRG imagery for eastern australia. Remote Sensing 5, 83-109. doi:10. $3390 /$ rs5010083

Hansen, M.C., Roy, D.P., Lindquist, E., Adusei, B., Justice, C.O., Altstatt, A., 2008. A method for integrating MODIS and Landsat data for systematic monitoring of forest cover and change in the Congo Basin. Remote Sensing of Environment 112, 2495-2513. doi:10.1016/j.rse.2007.11.012.

Higgins, M.A., Asner, G.P., Anderson, C.B., Martin, R.E., Knapp, D.E., Tu-

payachi, R., Perez, E., Elespuru, N., Alonso, A., 2015. Regional-Scale Drivers of Forest Structure and Function in Northwestern Amazonia. PLoS ONE 
10, e0119887. URL:http://dx.doi.org/10.1371/journal.pone.0119887) doi:10.1371/journal.pone.0119887.

Higgins, M.A., Asner, G.P., Perez, E., Elespuru, N., Tuomisto, H., Ruokolainen, K., Alonso, A., 2012. Use of Landsat and SRTM data to detect broad-scale biodiversity patterns in Northwestern Amazonia. Remote Sensing 4, 24012418. doi:10.3390/rs4082401.

Higgins, M.A., Ruokolainen, K., Tuomisto, H., Llerena, N., Cardenas, G., Phillips, O.L., Vásquez, R., Räsänen, M., 2011. Geological control of floristic composition in Amazonian forests. Journal of Biogeography 38, 2136-2149. doi: $10.1111 / \mathrm{j} .1365-2699.201 .02585 . \mathrm{x}$.

Hoorn, C., Wesselingh, F., ter Steege, H., Bermudez, M., Mora, A., Sevink, J., Sanmartín, I., Sanchez-Meseguer, A., Anderson, C., Figueiredo, J., Jaramillo, C., Riff, D., Negri, F., Hooghiemstra, H., Lundberg, J., Stadler, T., Särkinen, T., Antonelli, A., 2010. Amazonia through time: Andean uplift, climate change, landscape evolution, and biodiversity. Science 330, 927-931.

Irion, G., Kalliola, R., 2009. Long-term landscape development processes in Amazonia, in: Hoorn, C., Wesselingh, F.P. (Eds.), Amazonia: Landscape and Species Evolution: A look into the past. Wiley-Blackwell Publishing Ltd., p. 185.

Jaccard, P., 1912. The distribution of flora in the alpine zone. New Phytologist $11,37-50$.

Ju, J., Roy, D.P., Vermote, E., Masek, J., Kovalskyy, V., 2012. Continentalscale validation of MODIS-based and LEDAPS Landsat ETM+ atmospheric

correction methods. Remote Sensing of Environment 122, 175-84. doi:10. $1016 /$ j.rse.2011.12.025.

Kinupp, V., Magnusson, W., 2005. Spatial patterns in the understory shrub genus Psychotria in central Amzonia: effects of distance and topography. Journal of Tropical Ecology 21, 363-374. doi:10.1017/S0266467405002440. 
Kristiansen, T., Svenning, J.C., Eiserhardt, W.L., Pedersen, D., Brix, H., Kristiansen, S.M., Knadel, M., Grández, C., Balslev, H., 2012. Environment versus dispersal in the assembly of western Amazonian palm communities.

q Journal of Biogeography 39, 1318-1332. doi 10.1111/j.1365-2699.2012. $02689 \cdot x$.

Legendre, P., Legendre, L., 2012. Numerical ecology. 3rd ed., Elsevier, Amsterdam, The Netherlands.

Li, F., Jupp, D.L.B., Reddy, S., Lymburner, L., Mueller, N., Tan, P., Islam, A., 2010. An Evaluation of the Use of Atmospheric and BRDF Correction to Standardize Landsat Data. IEEE Journal of Selected Topics in Applied

575 \ Earth Observations and Remote Sensing 3, 257-270. doi 10.1109/JSTARS. 2010.2042281.

Li, F., Jupp, D.L.B., Thankappan, M., Lymburner, L., Mueller, N., Lewis, A., Held, A., 2012. A physics-based atmospheric and BRDF correction for Landsat data over mountainous terrain. Remote Sensing of Environment 124, 756-770. doi:10.1016/j.rse.2012.06.018,

Marengo, J.A., 1998. Climatología de la zona de Iquitos, Perú. Geología y desarrollo Amazónico, estudio integrado de la zona de Iquitos, Perú , 35-57.

Masek, J.G.M., Vermote, E.F., Saleous, N.E., Wolfe, R., Hall, F.G., Huemmrich, K.F., Gao, F., Kutler, J., Lim, T., 2006. A Landsat surface reflectance dataset for North America, 1990-2000. IEEE Geoscience and Remote Sensing Letters 3, 68-72. doi $10.1109 /$ lgrs.2005.857030.

Nagol, J.R., Sexton, J.O., Kim, D.H., Anand, A., Morton, D., Vermote, E., Townshend, J.R., 2015. Bidirectional effects in Landsat reflectance estimates: Is there a problem to solve? ISPRS Journal of

590 ( Photogrammetry and Remote Sensing 103, 129-135. URL: http://www. 1] sciencedirect.com/science/article/pii/S0924271614002317, doi,10. $1016 /$ j.isprsjprs.2014.09.006 
Phillips, O.L., Núñez Vargas, P., Monteagudo, A.L., Cruz, A.P., Zans, M.E.C., G., S.W., Yli-Halla, M., Rose, S., 2003. Habitat association among amazonian tree species: a landscape-scale approach. Journal of Ecology 91, 757-775. doi:10.1046/j.1365-2745.2003.00815.x.

Pires, J.M., Prance, G.T., 1985. The vegetation types of the Brazilian Amazon, in: Prance, G.T., Lovejoy, T.E. (Eds.), Key enironments: Amazonia. Pergamon, Oxford, pp. 109-145.

Poulsen, A.D., Tuomisto, H., Balslev, H., 2006. Edaphic and floristic variation 口 within a 1-ha plot of lowland Amazonian rain forest. Biotropica 38. doi 10. $1111 / \mathrm{j} .1744-7429.2006 .00168 . \mathrm{x}$.

Räsänen, M.E., Linna, A.M., Santos, J.C.R., Negri, F.R., 1995. Late Miocene 口 tidal deposits in the Amazonian foreland basin. Science 269, 386-390. doi 10. $1126 /$ science.269.5222.386.

Rebata-H., L.A., Gingras, M.K., Rasanen, M.E., Barberi, M., 2006. Tidalchannel deposits on a delta plain from the Upper Miocene Nauta Formation,

n Maranon Foreland Sub-basin, Peru. Sedimentology 53, 971-1013. doi 10. $1111 / \mathrm{j} .1365-3091.2006 .00795 . \mathrm{x}$

Roy, D.P., Ju, J., Kline, K., Scaramuzza, P.L., Kovalskyy, V., Hansen, M., Loveland, T.R., Vermote, E., Zhang, C., 2010. Web-enabled Landsat Data (weld): Landsat ETM+ composited mosaics of the conterminous United States. Remote Sensing of Environment 114, 35-49. doi $10.1016 / j . r s e .2009 .08 .011$

Roy, D.P., Ju, J., Lewis, P., Schaaf, C., Gao, F., Hansen, M., Lindquist, E., 2008. Multi-temporal MODIS-Landsat data fusion for relative radiometric normalization, gap filling, and prediction of Landsat data. Remote Sensing of Environment 112, 3112-3130. doi:10.1016/j.rse.2008.03.009.

Roy, D.P., Qin, Y., Kovalskyy, V., Vermote, E.F., Ju, J., Egorov, A., Hansen, M.C., Kommareddy, I., Yan, L., 2014. Conterminous United States demonstration and characterization of MODIS-based Landsat ETM+ atmospheric 
\ correction. Remote Sensing of Environment 140, 433-449. doi:10.1016/j. rse.2013.09.012

Roy, D.P., Zhang, H.K., Ju, J., Gomez-Dans, J.L., Lewis, P.E., Schaaf, C.B., Sun, Q., Li, J., Huang, H., Kovalskyy, V., 2016. A general method to normalize Landsat reflectance data to nadir BRDF adjusted re-

1] flectance. Remote Sensing of Environment 176, 255-271. URL: http://www.

sciencedirect.com/science/article/pii/S0034425716300220 doi 10. $1016 / \mathrm{j} \cdot \mathrm{rse} .2016 .01 .023$

Ruokolainen, K., Linna, A., Tuomisto, H., 1997. Use of Melastomataceae and pteridophytes for revealing phytogeographical patterns in Amazonian rain forests. Journal of Tropical Ecology 13, 243-256.

Ruokolainen, K., Tuomisto, H., 1998. Vegetación natural de la zona de Iquitos, in: Kalliola, R., Flores, S. (Eds.), Geoecología y desarrollo amazonico: estudio integrado en la zona de Iquitos, Perú. Annales Universitatis Turkuensis, Ser A II, vol 114, pp. S253-S365.

Ruokolainen, K., Tuomisto, H., Macía, M.J., Higgins, M.A., Yli-Halla, M., 2007. Are floristic and edaphic patterns in Amazonian rain forests congruent for trees, pteridophytes and Melastomataceae? Journal of Tropical Ecology 23, 13-25. doi:10.1017/S0266467406003889.

Salo, J., Kalliola, R., Häkkinen, I., Mäkinen, Y., Niemelä, P., Puhakka, M., Coley, P.D., 1986. River dynamics and the diversity of Amazon lowland forest. Nature 322, 254-258.

Schaaf, C.B., Gao, F., Strahler, A.H., Lucht, W., Li, X.W., Tsang, T., Strugnell, N., Zhang, X.Y., Jin, Y.F., Muller, J.P., Lewis, P., Barnsley, M., Hobson, P., Disney, M., Roberts, G., Dunderdale, M., Doll, C., d'Entremont, R.P., Hu, B.X., Liang, S.L., Privette, J.L., Roy, D., 2002. First operational BRDF, albedo and nadir reflectance products from MODIS. Remote Sensing of Environment 83, 135-148. doi:10.1016/S0034-4257(02)00091-3. 
Sesnie, S.E., Finegan, B., Gessler, P.E., Thessler, S., Ramos Bendana, Z., Smith, with support vector machines and Random Forest decision trees. International Journal of Remote Sensing 31, 2885-2909. doi 10.1080/01431160903140803|

Shuai, Y., Masek, J.G., Gao, F., Schaaf, C.B., He, T., 2014. An approach for the long-term $30-\mathrm{m}$ land surface snow-free albedo retrieval from historic Landsat surface reflectance and MODIS-based a priori anisotropy knowledge. Remote Sensing of Environment 152 ,

1] 467-479. URL: http://wWw.sciencedirect.com/science/article/pii/ S0034425714002545, doi $10.1016 /$ j.rse.2014.07.009,

Silva, F.B., Shimabukuro, Y.E., Aragão, L.E.O.C., Anderson, L.O., Pereira, G., Cardozo, F., Arai, E., 2013. Large-scale heterogeneity of Amazonian phenology revealed from 26-year long AVHRR/NDVI time-series. Environmental Research Letters 8, 024011. doi:10.1088/1748-9326/8/2/024011.

Thessler, S., Ruokolainen, K., Tuomisto, H., Tomppo, E., 2005. Mapping gradual landscape-scale floristic changes in Amazonian primary rain forests by combining ordination and remote sensing. Global Ecology and Biogeography 14, 315-325. doi:10.1111/j.1466-822x.2005.00158.x

Toivonen, T., Kalliola, R., Ruokolainen, K., Malik, R.N., 2006. Across-path DN gradient in Landsat TM imagery of Amazonian forests: A challenge for image interpretation and mosaicing. Remote Sensing of Environment 100, 550-562. doi: $10.1016 /$ j.rse.2005.10.006.

Tuomisto, H., Poulsen, A.D., Ruokolainen, K., Moran, R.C., Quintana, C., Celi, J., Cañas, G., 2003a. Linking floristic patterns with soil heterogeneity and satellite imagery in Ecuadorian Amazonia. Ecological Applications 13, 352-371. doi:10.1890/1051-0761(2003)013 [0352:LFPWSH] 2.0.C0;2.

675 Tuomisto, H., Ruokolainen, K., Aguilar, M., Sarmiento, A., 2003b. Floristic patterns along a 43-km long transect in an Amazonian rain forest. Journal of Ecology 91, 743-756. doi:10.1046/j.1365-2745.2003.00802.x. 
Tuomisto, H., Ruokolainen, K., Kalliola, R., Linna, A., Danjoy, W., Rodriguez,

п Z., 1995. Dissecting Amazonian biodiversity. Science 269, 63-66. doi-10. 1126/science.269.5220.63.

Tuomisto, H., Ruokolainen, K., Yli-Halla, M., 2003c. Dispersal, environment, and floristic variation of western Amazonian forests. Science 299, 241-244. doi:10.1126/science.1078037

Wulder, M.A., Masek, J.G., Cohen, W.B., Loveland, T.R., Woodcock, C.E., 2012. Opening the archive: How free data has enabled the science and monitoring promise of Landsat. Remote Sensing of Environment 122, 2-10. 


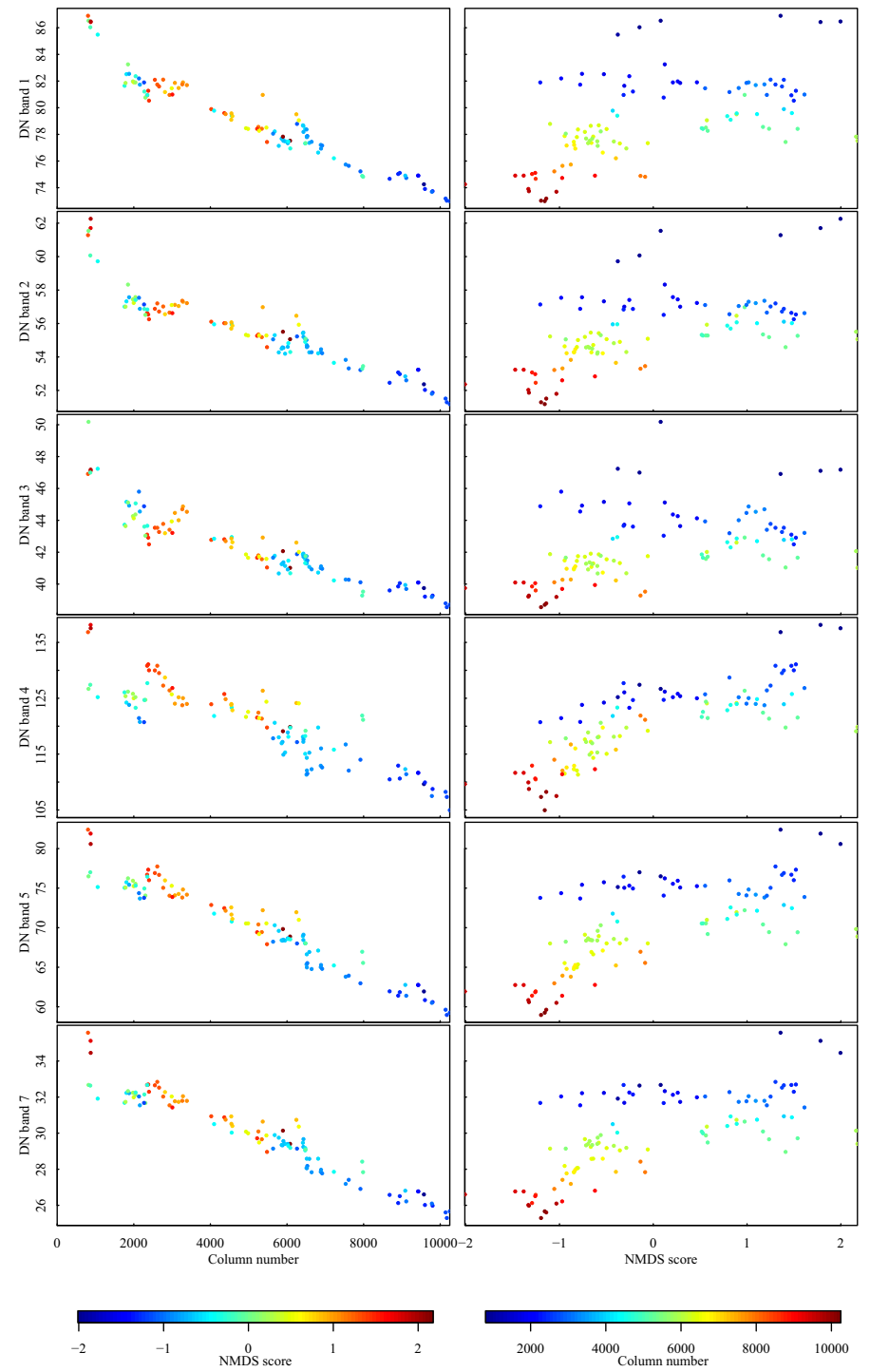

Figure 5: $D N$ versus column number (left) and $D N$ versus NMDS score (right) for 105 transects in Peru. 


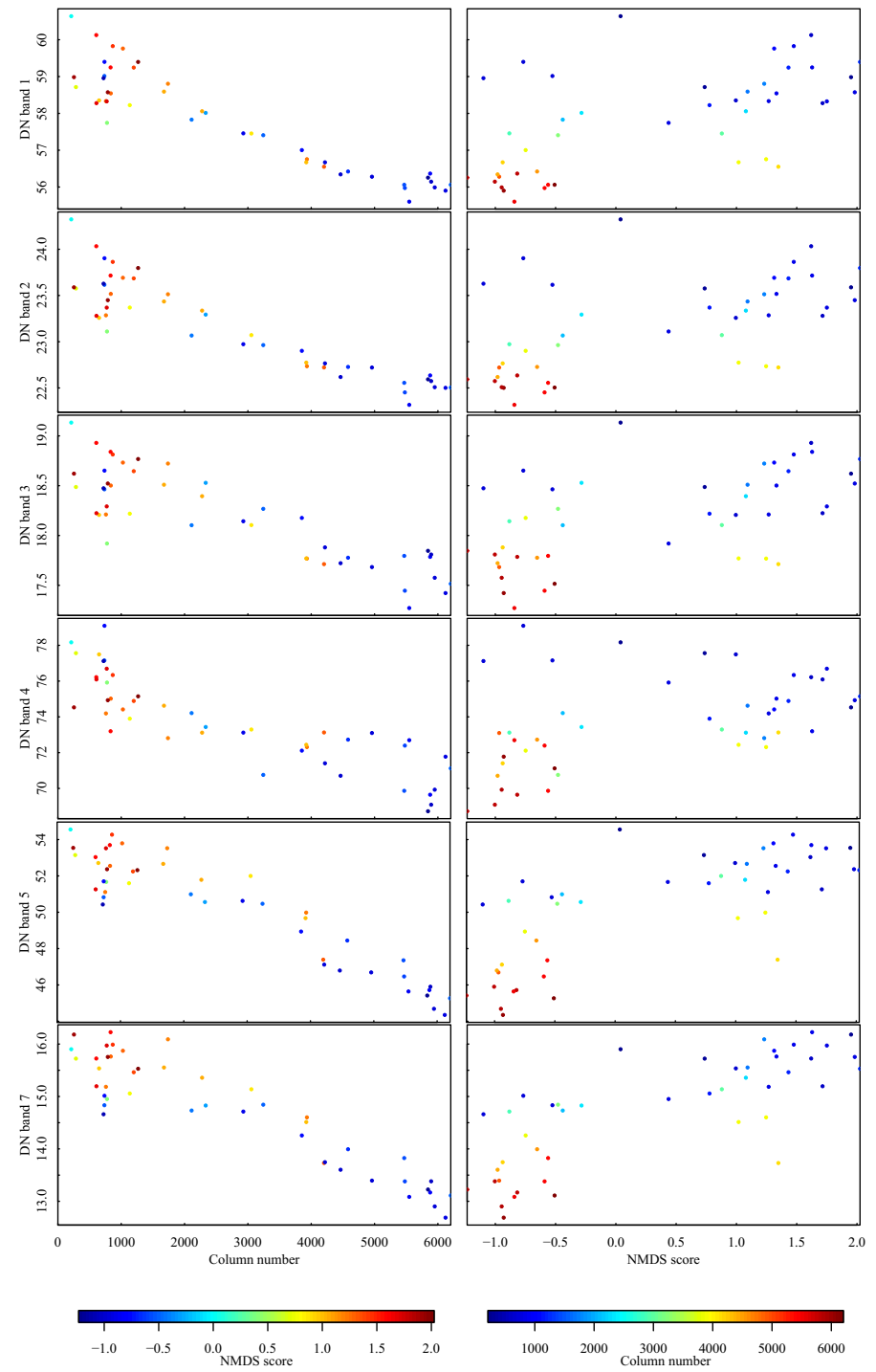

Figure 6: $D N$ versus column number (left) and $D N$ versus NMDS score (right) for 45 transects in Brazil. 
Table 2: $\bar{R}^{2}$ values for the iterative regression analyses between digital number and column number $(\Gamma)$ and NMDS score $(\nu)$, for the Peruvian and Brazilian Landsat TM/ETM+ mosaics.

\begin{tabular}{|c|c|c|c|c|}
\hline & Peru & & Brazil & \\
\hline & Predictors & $\bar{R}^{2}$ & Predictors & $\bar{R}^{2}$ \\
\hline & $\Gamma$ & 0.924 & $\Gamma$ & 0.848 \\
\hline$\vec{z}$ & $\Gamma+\nu$ & 0.923 & $\Gamma+\nu$ & 0.845 \\
\hline & $\Gamma+\nu+\Gamma^{2}$ & 0.940 & & \\
\hline & $\Gamma+\nu+\Gamma^{2}+\Gamma^{3}$ & 0.972 & & \\
\hline & $\Gamma$ & 0.857 & $\Gamma$ & 0.823 \\
\hline v & $\Gamma+\nu$ & 0.857 & $\Gamma+\nu$ & 0.820 \\
\hline$\tilde{\omega}^{\tilde{n}}$ & $\Gamma+\nu+\Gamma^{2}$ & 0.875 & & \\
\hline & $\Gamma+\nu+\Gamma^{2}+\Gamma^{3}$ & 0.927 & & \\
\hline & $\Gamma+\nu+\Gamma^{2}+\Gamma^{3}+\nu^{3}$ & 0.929 & & \\
\hline & $\Gamma$ & 0.842 & $\Gamma$ & 0.723 \\
\hline ? & $\Gamma+\nu$ & 0.848 & $\Gamma+\nu$ & 0.717 \\
\hline$\tilde{\oplus}$ & $\Gamma+\nu+\Gamma^{2}$ & 0.879 & & \\
\hline & $\Gamma+\nu+\Gamma^{2}+\Gamma^{3}$ & 0.905 & & \\
\hline & $\Gamma$ & 0.779 & $\Gamma$ & 0.729 \\
\hline$\vec{z}$ & $\Gamma+\nu$ & 0.881 & $\Gamma+\nu$ & 0.746 \\
\hline$\ddot{\oplus}$ & $\Gamma+\nu+\Gamma \nu$ & 0.890 & $\Gamma+\nu+\Gamma \nu$ & 0.885 \\
\hline & $\Gamma+\nu+\Gamma \nu+\Gamma \nu^{2}$ & 0.903 & $\Gamma+\nu+\Gamma \nu+\Gamma \nu^{2}$ & 0.900 \\
\hline & $\Gamma$ & 0.936 & $\Gamma$ & 0.869 \\
\hline$\frac{10}{7}$ & $\Gamma+\nu$ & 0.956 & $\Gamma+\nu$ & 0.891 \\
\hline$\tilde{\oplus}$ & $\Gamma+\nu+\Gamma \nu$ & 0.958 & $\Gamma+\nu+\Gamma^{2}$ & 0.908 \\
\hline & $\Gamma+\nu+\Gamma \nu+\Gamma^{2} \nu$ & 0.961 & & \\
\hline & $\Gamma+\nu+\Gamma \nu+\Gamma^{2} \nu+\nu^{3}$ & 0.963 & & \\
\hline & $\Gamma$ & 0.933 & $\Gamma$ & 0.848 \\
\hline$\vec{z}$ & $\Gamma+\nu$ & 0.951 & $\Gamma+\nu$ & 0.899 \\
\hline$\tilde{\oplus}$ & $\Gamma+\nu+\Gamma \nu$ & 0.953 & $\Gamma+\nu+\Gamma^{2}$ & 0.907 \\
\hline & $\Gamma+\nu+\Gamma \nu+\Gamma^{2} \nu$ & 0.958 & & \\
\hline
\end{tabular}


Table 3: Means and standard deviations of the slopes of linear regression of reflectance versus column number over Pebas and Nauta formation forests and the difference between their means (all unitless and all $\times 10^{6}$ ) for each Landsat TM/ETM+ band, per scene and for all scenes pooled. Asterisks indicate non-normal distribution according to Shapiro-Wilks test, superscripts ${ }^{t}$ and $w$ indicate significant differences for the t-test and Wilcoxon test, respectively (all at $\mathrm{p}=0.05$ )

\begin{tabular}{lllllll}
\hline \multirow{2}{*}{ Scene } & \multicolumn{5}{c}{ Pebas } & \multicolumn{2}{c}{ Nauta } \\
\hline 003/064 & 1 & -0.9299 & $1.1181^{*}$ & -0.5280 & 0.7060 & -0.4020 \\
& 2 & -0.7840 & $0.8208^{*}$ & -0.4204 & 0.5329 & -0.3636 \\
& 3 & -0.2456 & 0.3708 & -0.1574 & 0.4669 & -0.0882 \\
& 4 & -6.1178 & 2.5038 & -3.3766 & 1.0596 & $-2.7412^{t, w}$ \\
& 5 & -4.0358 & $1.3477^{*}$ & -2.9620 & 0.7976 & $-1.0738^{t, w}$ \\
& 7 & -1.8789 & $0.6976^{*}$ & -1.2619 & 0.4385 & $-0.6170^{t, w}$ \\
\hline $007 / 062$ & 1 & -1.0706 & 0.5193 & -0.8320 & 0.6532 & -0.2386 \\
& 2 & -0.9853 & 0.4352 & -0.7761 & 0.5046 & -0.2093 \\
& 3 & -0.5138 & 0.4091 & -0.2923 & 0.5388 & $-0.2215^{t}$ \\
& 4 & -6.9189 & 2.1561 & -7.0125 & 1.4243 & 0.0936 \\
& 5 & -4.2102 & 0.7976 & -4.5051 & 0.7818 & 0.2949 \\
& 7 & -1.8172 & 0.5909 & -1.9635 & 0.6023 & 0.1463 \\
\hline $008 / 062$ & 1 & -0.6820 & $1.5101^{*}$ & -0.7758 & $0.8906^{*}$ & 0.0938 \\
& 2 & -0.6617 & $1.1511^{*}$ & -0.8976 & $0.6292^{*}$ & 0.2359 \\
& 3 & -0.1517 & $0.9404^{*}$ & -0.2192 & $0.5173^{*}$ & 0.0676 \\
& 4 & -6.6532 & 1.7389 & -8.9520 & 1.8638 & $2.2987^{t, w}$ \\
& 5 & -3.9889 & 0.9475 & -4.5632 & 1.0401 & $0.5742^{t, w}$ \\
& 7 & -1.9235 & 0.5365 & -2.0963 & 0.4808 & $0.1728^{t, w}$ \\
\hline \multirow{2}{*}{ Combined } & 1 & -0.8966 & $1.1103^{*}$ & -0.6996 & 0.7486 & -0.1969 \\
& 2 & -0.8086 & $0.8423^{*}$ & -0.6795 & $0.5827^{*}$ & -0.1290 \\
& 5 & -0.2998 & $0.6192^{*}$ & -0.2186 & 0.4973 & -0.0812 \\
& & -6.5336 & 2.1599 & -6.2423 & 2.7806 & -0.2913 \\
& -4.0755 & 1.0594 & -3.9402 & 1.1516 & -0.1353 \\
& -1.8736 & 0.6058 & -1.7398 & 0.6245 & -0.1338 \\
\hline & & & & &
\end{tabular}


Table 4: Means and standard deviations of the slopes of linear regression of reflectance versus column number, either stratified based on geological formation or unstratified, and the difference between their means (all unitless and all $\times 10^{6}$ ) for each Landsat TM/ETM+ band, per scene. Asterisks indicate non-normal distribution according to Shapiro-Wilks test, superscripts ${ }^{t}$ and $w$ indicate significant differences for the t-test and Wilcoxon test, respectively (all at $\mathrm{p}=0.05$ ).

\begin{tabular}{lllllll}
\hline & & \multicolumn{2}{c}{ Stratified } & \multicolumn{2}{c}{ Unstratified } \\
Scene & Band & Mean & St. dev. & Mean & St. dev. & Difference \\
\hline $003 / 064$ & 1 & -0.7289 & 0.5625 & -0.7373 & 0.4008 & 0.0084 \\
& 2 & -0.6022 & 0.4596 & -0.7815 & 0.3730 & $0.1793^{t, w}$ \\
& 3 & -0.2015 & $0.3091^{*}$ & -0.2053 & $0.2714^{*}$ & 0.0038 \\
& 4 & -4.7472 & 1.5206 & -7.6987 & 1.7555 & $2.9514^{t, w}$ \\
& 5 & -3.4989 & 1.0215 & -5.0451 & 1.1189 & $1.5461^{t, w}$ \\
& 6 & -1.5704 & 0.5403 & -2.4040 & 0.6357 & $0.8336^{t, w}$ \\
\hline $007 / 062$ & 1 & -0.9513 & 0.5429 & -0.9248 & 0.4326 & -0.0264 \\
& 2 & -0.8807 & 0.4151 & -0.7552 & 0.3266 & $-0.1256^{t, w}$ \\
& 3 & -0.4031 & 0.4421 & -0.3920 & 0.3441 & -0.0110 \\
& 4 & -6.9657 & 1.5497 & -5.6448 & 1.4250 & $-1.3209^{t, w}$ \\
& 5 & -4.3576 & 0.6684 & -3.7911 & 0.6432 & $-0.5665^{t, w}$ \\
& 6 & -1.8904 & 0.5392 & -1.6300 & 0.5198 & $-0.2604^{t, w}$ \\
\hline $008 / 062$ & 1 & -0.7289 & $1.1833^{*}$ & -0.7317 & $1.1708^{*}$ & 0.0028 \\
& 2 & -0.7797 & $0.8746^{*}$ & -0.7016 & $0.8481^{*}$ & $-0.0780^{t, w}$ \\
3 & -0.1855 & $0.7149^{*}$ & -0.2206 & $0.7004^{*}$ & 0.0351 \\
& 4 & -7.8026 & 1.5830 & -6.4770 & 1.6745 & $-1.3257^{t, w}$ \\
& 5 & -4.2760 & 0.9587 & -3.7931 & 1.0045 & $-0.4829^{t, w}$ \\
6 & -2.0099 & 0.4930 & -1.7369 & 0.5099 & $-0.2730^{t, w}$ \\
\hline
\end{tabular}

